\title{
Structure and Phase Transitions of Ethyl 4'-n-undecyloxybiphenyl-4-carboxylate and its Acid Derivative
}

\author{
Delia López-Velázquez ${ }^{1}$, Armando R. Hernández-Sosa ${ }^{1}$, Sylvain Bernès ${ }^{2}$, Ernesto Pérez ${ }^{3}$, \\ Juan P. Fernández-Blázquez ${ }^{3}$ \\ ${ }^{1}$ Facultad de Ciencias Químicas, BUAP, Ciudad Universitaria, Boulevard 14 sur, \\ Col. San Manuel. C.P. 72570 Puebla, Puebla, Mexico \\ ${ }^{2}$ DEP, Facultad de Ciencias Químicas, UANL, Guerrero y Progreso S/N, Col. Treviño, 64570 \\ Monterrey, N.L., Mexico \\ ${ }^{3}$ Instituto de Ciencia y Tecnología de Polímeros, CSIC, Juan de la Cierva 3, 28006 Madrid, Spain
}

\begin{abstract}
Ethyl 4'-n-undecyloxybiphenyl-4-carboxylate, 2(11)OBC, and 4'-n-undecyloxybiphenyl-4carboxylic acid, (11)OBC, are smectic liquid crystals precursors of low molecular weight premesogens, and of potential liquid crystal macromolecules. The single-crystal X-ray study of 2(11)OBC showed that it crystallizes in a non-centrosymmetric space group with molecules stacked along the short axis [010] and [001] without significant $\pi \ldots \pi$ or $\mathrm{CH}_{\ldots} \ldots \pi$ interactions. Such an arrangement may explain its strong tendency to form smectic mesophases. Both biphenyl derivatives have a rich polymesomorphism whose phase sequences were determined by DSC, optical microscopy and diffraction profiles using synchrotron radiation. These profiles indicated quite similar phase transitions in the two samples, although very different transition temperatures. Thus, the phase transitions (on cooling) of 2(11)OBC are: Isotropic $\rightarrow \operatorname{SmA}\left(101{ }^{\circ} \mathrm{C}\right) \rightarrow \mathrm{SmB}$ $\left(88{ }^{\circ} \mathrm{C}\right) \rightarrow \mathrm{SE}\left(79^{\circ} \mathrm{C}\right) \rightarrow$ crystal phase $\left(43^{\circ} \mathrm{C}\right)$, while those (on cooling) of (11)OBC are the following: Isotropic $\rightarrow \operatorname{SmA}\left(246{ }^{\circ} \mathrm{C}\right) \rightarrow \operatorname{SmB}\left(192{ }^{\circ} \mathrm{C}\right) \rightarrow \operatorname{SX}\left(162{ }^{\circ} \mathrm{C}\right) \rightarrow \operatorname{SE}\left(148{ }^{\circ} \mathrm{C}\right) \rightarrow$ crystal phase $\left(62{ }^{\circ} \mathrm{C}\right)$. The much higher transition temperatures for the acid derivative are explained by considering that this molecule forms dimers through classical $\mathrm{O}-\mathrm{H}$...O hydrogen bonds involving the carboxylic groups.
\end{abstract}


Keywords: biphenyl derivatives; single crystal X-ray diffraction; liquid crystal polymesomorphism; synchrotron diffraction.

\section{INTRODUCTION}

Biphenyl derivatives have been extensively studied because of their application in liquid crystal displays. ${ }^{1}$ Furthermore, biphenyl esters and their acids are able to undergo functionalization reactions, providing access to a variety of compounds. ${ }^{2}$ On the other hand, liquid crystalline polymers with mesogenic side chains (SCLCPs) have attracted special interest because of the possible applications in the fields of non-linear optics, optical storage and electro-

optic displays. ${ }^{3}$ SCLCPs can be obtained either by chemical modification of a prepolymer with a functionalized liquid crystal or by polymerization of a liquid crystal monomer.

Gray et $a l .{ }^{4}$ synthesized and studied the mesomorphic behavior of some 4'- $n$ alkoxybiphenyl-4-carboxylates [structure $(\boldsymbol{m}) \mathbf{O B C}$ in Scheme 1], and their ester derivatives $n$ alkyl-4'-n-alkoxybiphenyl-4-carboxylates, $\boldsymbol{n}(\boldsymbol{m}) \mathbf{O B C}$ (Scheme 1) where $\boldsymbol{n}=1-3$ is the number of $\mathrm{C}$ atoms of the aliphatic alcohol derivative, and $\boldsymbol{m}=1-10,12,16,18$ is the number of $\mathrm{C}$ atoms in the alkyl tail. However, they did not synthesize (11)OBC, neither the derived ester 2(11)OBC, which will be described in this paper. They reported that the acids with $\boldsymbol{m}=1-4$ are not mesomorphic, while the acids with $\boldsymbol{m}=5-10$ develop smectic-nematic mesophases, and those with $\boldsymbol{m}=12,16$ and 18 develop only smectic phases. In the case of their ethyl esters $\mathbf{2}(\boldsymbol{m}) \mathbf{O B C}$ they described that the first four members with $\boldsymbol{m}=1-4$ are non-mesomorphic, while the other nine ethyl esters, corresponding to $\boldsymbol{m}=5-10,12,16$ and 18 , develop only smectic phases. In their work they did not report DSC or X-ray analysis for none of the acids and corresponding ethyl esters. Therefore, the accurate types of mesophases were not described.

It should be also mentioned that Isoo and coworkers ${ }^{5}$ reported isomers of (11)OBC $\left(\mathrm{C}_{24} \mathrm{H}_{32} \mathrm{O}_{3}\right)$, and its ethyl ester 2(11)OBC $\left(\mathrm{C}_{26} \mathrm{H}_{36} \mathrm{O}_{3}\right)$. However, these isomers belong to a family of chiral esters whose general formula is given in Scheme 2.

Therefore, the importance of ethyl 4'-n-undecyloxybiphenyl-4-carboxylate and its acid stems from their ability to potentially undergo functionalization reactions, providing access to a variety of compounds. 
We report here the analysis by DSC, optical microscopy and synchrotron X-ray diffraction of the phase transitions for (11)OBC and 2(1)OBC. Moreover, with the aim of gaining insight in the packing patterns of the 2(11)OBC mesogenic arrangement, its room-temperature structure was also determined by single crystal X-ray analysis. Such a solid-state structural analysis was unfortunately not achieved for (11)OBC, due to the poor solubility of this acid, avoiding growth of suitable single crystals.

\section{EXPERIMENTAL}

Ethyl-4'-hydroxy-4-biphenylcarboxylate (98\%), chloroform-d (99.9\%), (methyl sulfoxide)$\mathrm{d}_{6}(99.9 \%)$ and 1-bromo-undecane $(99 \%)$ were purchased from Sigma-Aldrich and were used as received. Dimethylformamide (DMF) was purified according to a standard procedure. Other chemicals were of reagent grade and used without further purification. The chemical structures of all the materials prepared, intermediates and final products, were analyzed by a combination of nuclear magnetic resonance spectroscopy (NMR), infrared spectroscopy (FTIR) and C, H elemental analysis. Analytical data were found to be fully consistent with the assigned structures.

${ }^{1} \mathrm{H}$-NMR and ${ }^{13} \mathrm{C}$-NMR spectra were acquired with a Varian $(400 \mathrm{MHz})$ spectrometer. The NMR samples were prepared as $10-20 \%(\mathrm{w} / \mathrm{v})$ solutions in $\mathrm{CDCl}_{3}$ or DMSO- $d_{6}$. Spectra were usually recorded at room temperature.

FTIR analyses were performed on a Perkin-Elmer Spectrum One spectrometer. The samples were prepared by dissolving the material in a volatile solvent, placing a few drops of the solution on a diamond cell, and then allowing the solvent to evaporate.

Diffraction data for 2(11)OBC were collected at $23{ }^{\circ} \mathrm{C}$ on a Bruker P4 diffractometer, using standard procedures ${ }^{6}$ and the structure solved and refined using the SHELX97 package ${ }^{7}$. Measured Friedel pairs were merged in the final least-squares cycles, since no significant anomalous scattering effects are produced by this organic crystal. Bond length $\mathrm{C} 16-\mathrm{C} 17$ was restrained to 1.53(1) $\AA$, otherwise an unreasonably short bond length was obtained at convergence, probably because of an unresolved disorder. All $\mathrm{H}$ atoms were placed in calculated positions and refined isotropically using a riding model approximation. Further details and complete geometric data may be obtained from the archived CIF, and raw diffraction data are available on request. 
The thermal behavior of 2(11)OBC and (11)OBC was studied by thermogravimetric analysis (TGA) and differential scanning calorimetry (DSC). Subsequently, the nature of the phases involved was analyzed by optical microscopy and by real-time diffraction experiments. The thermogravimetric analysis was carried out with a Q50 Thermal Analysis Instrument, equipped with the Thermal Advantage software. Analyses were performed under a nitrogen gas flow $(20 \mathrm{ml} / \mathrm{min})$ with a heating rate of $10^{\circ} \mathrm{C} / \mathrm{min}$.

A Perkin-Elmer DSC7 Calorimeter equipped with an auto-cool accessory and Thermal Analysis Data Station was employed for DSC studies. The scans were carried out under a nitrogen atmosphere. Transition temperatures were collected during heating and cooling scans, at different rates: $20^{\circ} \mathrm{C} / \mathrm{min}$ for (11)OBC and $8^{\circ} \mathrm{C} / \mathrm{min}$ for 2(11)OBC, and for several cycles

A Carl-Zeiss Amplival D microscope, in conjunction with a Linkam TMS92 hot stage with its control unit, was used for the Polarized Optical Microscopy (POM) experiments. This microscope was also equipped with a video camera.

Real-time variable-temperature X-ray scattering experiments were performed using synchrotron radiation $(\lambda=0.150 \mathrm{~nm})$ in the soft-condensed matter beam-line A2 at HASYLAB (Hamburg, Germany). A MAR-CCD detector placed at a distance of $169 \mathrm{~mm}$ from the sample was used, covering the spacings interval from around 10 to $0.3 \mathrm{~nm}$ (wide, WAXS, and middleangle scattering, MAXS, regions). The detector calibration for spacings was made with a sample of silver behenate $\left(\mathrm{AgC}_{22} \mathrm{H}_{43} \mathrm{O}_{2}\right)$, which gives a well-defined diffraction at a spacing of $5.838 \mathrm{~nm}$, and several other orders spacings.

\section{Synthesis and characterization of 2(11)OBC, $\mathrm{C}_{26} \mathrm{H}_{36} \mathrm{O}_{3}$}

Ethyl-4'-n-undecyloxybiphenyl-4-carboxylate was synthesized following a procedure reported in the literature. ${ }^{8}$ Basically, this compound was obtained by reacting ethyl 4'-hydroxy-4biphenylcarboxylate and 1-bromo- $n$-undecane in DMF at $100{ }^{\circ} \mathrm{C}$ for 24 hours (see Scheme 3). $90 \%$ yield. IR (ATR) 2917, 1714, 1602, 1284, $816 \mathrm{~cm}^{-1}$.

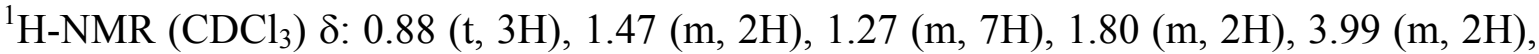
$6.99(\mathrm{~m}, 2 \mathrm{H}), 7.54(\mathrm{~d}, 2 \mathrm{H}), 7.62(\mathrm{~d}, 2 \mathrm{H}), 8.06(\mathrm{~d}, 2 \mathrm{H}), 4.38(\mathrm{~d}, 2 \mathrm{H}), 1.40(\mathrm{t}, 3 \mathrm{H})$.

${ }^{13} \mathrm{C}-\mathrm{NMR}\left(\mathrm{CDCl}_{3}\right) \delta: 166.62,159.44,145.19,132.21,130.05,128.53,128.31,126.39$, 114.93, 68.15, 60.88, 31.92, 29.62, 29.62, 29.41, 29.26, 26.06, 22.70, 14.38, 14.12.

Anal. Calcd for $\mathrm{C}_{26} \mathrm{H}_{36} \mathrm{O}_{3}$ : C 78.75, H 9.15. Found: C 78.88, H 9.18. 
Colorless single crystal, $0.60 \times 0.60 \times 0.14 \mathrm{~mm}^{3}$; monoclinic, $C c ; a=50.369(8), b=$ 7.5607(13), $c=6.1879(18) \AA, \beta=92.976(17)^{\circ}$; radiation: Mo- $K \alpha(\lambda=0.71073 \AA), \theta_{\max }=27.5^{\circ}$; 2685 unique data for 263 refined parameters; $R_{1}[I>2 \sigma(I)]=0.0579, w R_{2}$ [all data $]=0.1805$.

\section{Synthesis and characterization of (11)OBC, $\mathrm{C}_{24} \mathrm{H}_{32} \mathrm{O}_{3}$}

4'- $n$-Undecyloxybiphenyl-4-carboxylic acid was obtained by a classic saponification of its ester with sodium hydroxide, as described in Scheme 3. The sodium salt was acidified with acetic acid under reflux $\left(104^{\circ} \mathrm{C}\right)$ for $25 \mathrm{~min}$. After dissolution, the mixture was then allowed to cool to room-temperature, and subsequently cooled to $0{ }^{\circ} \mathrm{C}$. A microcrystalline powder which formed was collected by filtration, washed with large amounts of water, and dried under vacuum at 45 ${ }^{\circ} \mathrm{C}$, to yield $93 \%$ of white powder. IR (ATR) 3300-2900, 2917, 1685, 1603, 1290, $836 \mathrm{~cm}^{-1}$.

${ }^{1} \mathrm{H}-\mathrm{NMR}\left(\mathrm{DMSO}-d_{6}, 70{ }^{\circ} \mathrm{C}\right) \delta: 0.85(\mathrm{t}, 3 \mathrm{H}) ; 1.42(\mathrm{~m}, 2 \mathrm{H}) ; 1.25(\mathrm{~m}, 14 \mathrm{H}) ; 1.72(\mathrm{~m}, 2 \mathrm{H})$; 4.01 (t, 2H); 7.02 (d, 2H); $7.63(\mathrm{~d}, 2 \mathrm{H}) ; 7.72(\mathrm{~d}, 2 \mathrm{H}) ; 7.97$ (d, 2H).

${ }^{13} \mathrm{C}-\mathrm{NMR}\left(\mathrm{DMSO}-d_{6}, 70{ }^{\circ} \mathrm{C}\right.$ ) $\delta: 167.75,159.80,144.73,131.99,130.55,129.71,128.71$, $126.69,115.84,68.48,31.91,29.59,29.38,29.29,26.14,22.67,14.44$.

Anal. Calcd for $\mathrm{C}_{24} \mathrm{H}_{32} \mathrm{O}_{3}:$ C, 78.22; H, 8.75. Found: C, 78.27; H, 8.79.

\section{RESULTS AND DISCUSSION}

\section{Crystal structure of 2(11)OBC}

As expected, 2(11)OBC crystallizes in a strongly anisotropic unit-cell, with a long/short parameters ratio $a / c>8$. The molecule is built-up on a biphenyl core para-substituted by the ethyl ester and $n$-undecyloxy functional groups (Figure 1, inset). The latter presents an all-trans conformation, as found in the closely related derivative 4-cyano-4'-(n-undecyloxy)biphenyl. ${ }^{9}$ In 2(11)OBC, the dihedral angle between aromatic rings is $12.7(2)^{\circ}$, significantly smaller than that found in the cyano derivative $\left(31.4^{\circ}\right)$. However, this conformation is consistent with other parasubstituted biphenyl derivatives, for which dihedral angles fall in the range 0 to $60^{\circ}$. Such conformational variations are generally believed to be a consequence of crystal packing effects rather than steric or electronic effects. 
Rajnikant et al. structurally characterized a number of 4-cyano-4'-(n-alkyloxy)-biphenyl derivatives, namely with $m=8,{ }^{10} m=10,{ }^{11} m=11,{ }^{9}$ and $m=12^{11}$ alkyl chains. The case $m=8$, i.e. 4-cyano-4'-octoxybiphenyl, is of particular interest, since a transition to smectic phase has been detected at $54.5{ }^{\circ} \mathrm{C}^{10}$ Moreover, polymorphic phases have been reported for this molecule. ${ }^{12,13}$ As a common feature, all these molecules crystallize in centrosymmetric space groups. In contrast, 2(11)OBC crystallizes in a non-centrosymmetric space group, $C c$, allowing a different arrangement for molecules in the crystal, which, in turn, should facilitate the polymesomorphism observed for this biphenyl (see infra). Molecules are stacked along the short [010] and [001] axis (Figure 1) with aliphatic chains placed parallel within a stack. These stacks are repeated through translational symmetry operators, including $C$ cell centering. No significant $\pi \ldots \pi$ or $\mathrm{CH} . . . \pi$ intermolecular interactions are present in the crystal structure, a feature obviously related to the low melting point of 2(11)OBC.

For the acid (11)OBC, attempts to obtain single crystals were unsuccessful, its solubility being low and limited to some polar aprotic solvents, like acetone, DMF and DMSO. IR spectrum for this compound displays a broad O-H stretch vibration (3300-2900 $\left.\mathrm{cm}^{-1}\right)$, indicative of intermolecular hydrogen bonding, and a strong sharp band at $1685 \mathrm{~cm}^{-1}$ associated to $\mathrm{H}$ bonded carbonyl stretching. These bands are characteristic of centrosymmetric dimers formed through strong $\mathrm{O}-\mathrm{H} . . . \mathrm{O}$ hydrogen bonds involving carboxylic functionalities, ${ }^{14,15}$ and may explain both the high melting point and the low solubility ${ }^{16}$ observed for this compound.

\section{Thermal behavior of 2(11)OBC and (11)OBC}

The TGA of (11)OBC showed a good thermal stability up to $250{ }^{\circ} \mathrm{C}$ and a single-step weight loss with maximum loss rate at $366^{\circ} \mathrm{C}$ (Figure 2). The temperature for $9.91 \%$ weight loss was $284.2{ }^{\circ} \mathrm{C}$. The DSC curves of (11)OBC are shown in Figure 3 for the first melting and subsequent cooling. Several transitions are found in both curves. Thus, the melting curve shows four endothermic peaks (one of them of very small intensity) centered at 115.8, 172.2, 200.5 and $254.2{ }^{\circ} \mathrm{C}$, with enthalpies of $63.3,45.3,2.0$ and $56.0 \mathrm{~J} / \mathrm{g}$, respectively. The thermal transition data for (11)OBC, compared to those of its ethyl ester, are given in Tables 1 and 2. The phases involved in the different transitions will be analyzed in the section devoted to synchrotron diffraction data.

The DSC curves corresponding to 2(11)OBC are shown in Figure 4. Four transitions can be observed. Thus, the cooling curve shows four exothermic peaks, three of them very sharp (at 
$100.9,87.6$ and $78.7^{\circ} \mathrm{C}$ ) and a low-temperature one much broader, centered at $43.4^{\circ} \mathrm{C}$ and with the onset at $c a .50{ }^{\circ} \mathrm{C}$. The thermodynamic data for both the melting and cooling runs are presented in Tables 1 and 2, respectively, and can be compared to those computed for (11)OBC. It can be observed that the transition temperatures are much higher in the case of the acid, (11)OBC, a feature consistent with IR data and the assumed dimeric structure in the solid state.

All these phase transitions are reversible and do not change on repeated heating and cooling cycles. It should be pointed out that, in the case of the acid, the onset decomposition temperature is reached above $255^{\circ} \mathrm{C}$ (see Figure 2).

\section{Optical Textures of (11)OBC and 2(11)OBC}

When (11)OBC is cooled from the isotropic phase, the first birefringent texture is observed at ca. $240{ }^{\circ} \mathrm{C}$ (Figure 5a). On decreasing of the temperature, that texture coexists with a granulated one (Figure $5 \mathrm{~b}, T=230^{\circ} \mathrm{C}$ ). Considering that the first transition observed in the DSC experiment (Figure 3) has a low enthalpy and very low undercooling, the first phase formed from the isotropic melt may be assumed to be a low-ordered smectic mesophase. During the two following DSC transitions (exotherms at 162.1 and $148.3{ }^{\circ} \mathrm{C}$ ) the texture changes to a mosaic texture (Figure $5 \mathrm{c}, T=135^{\circ} \mathrm{C}$ ), and it is not possible to distinguish optical changes between both DSC transitions. This texture is typical of mesophases with higher order ${ }^{17,18}$. On further cooling, several lines appear superimposed on the mosaic structure (Figure $5 \mathrm{~d}, T=60^{\circ} \mathrm{C}$ ), corresponding to the last exothermic peak at $61.9^{\circ} \mathrm{C}$. Most probably, an ordered crystal structure has then been reached.

In the case of 2(11)OBC, the representative textures observed during the cooling from the isotropic melt are shown in Figure 6. A fan-shaped texture is first observed at $103{ }^{\circ} \mathrm{C}$ (Figure 6a). This texture, typical of a low ordered mesophase ${ }^{17-19}$, does not present important changes when cooling down to $85^{\circ} \mathrm{C}$, although variations in the light intensity can be observed (Figure 6b). At $75^{\circ} \mathrm{C}$, concentric arcs appear in the fan-shaped texture (Figure $6 \mathrm{c}$ ). This texture ${ }^{17}$ is characteristic of highly ordered smectic crystals, as for SE phases. Finally, a granulated texture is obtained at lower temperatures (Figure 6d), indicating, most probably ${ }^{18}$, that the system has crystallized.

\section{Synchrotron analysis}

Phase transitions of 2(11)OBC: The diffraction profiles corresponding to a cooling experiment similar to that used in the DSC experiments are shown in Figure 7. At high 
temperature, an amorphous halo is obtained in the WAXS channels, and no peak is observed in the MAXS region, as expected for the isotropic melt. Around $100{ }^{\circ} \mathrm{C}$, a sharp MAXS peak appears, centered at $2.870 \mathrm{~nm}$, but the WAXS profile is rather similar to that of the isotropic state, indicating the formation of a low-ordered smectic mesophase, most probably of the type SmA. At ca. $89^{\circ} \mathrm{C}$, the MAXS peak is shifted to $2.907 \mathrm{~nm}$, and a considerable narrowing of the WAXS diffractogram is observed. These features are typical of a mesophase with disordered hexagonal packing within the smectic layers (probably a SmB mesophase).

On further lowering the temperature, at $c a .79{ }^{\circ} \mathrm{C}$, the WAXS diffractogram shows a very important modification, since three narrow diffractions peaks (at spacings of $0.454,0.413$ and $0.328 \mathrm{~nm}$ ) are observed, while the MAXS peak changes only very slightly to a spacing of 2.915 $\mathrm{nm}$. These characteristics, together with the textures obtained by optical microscopy, support the formation of a highly ordered smectic crystal with orthorhombic packing, as for a SE phase.

Finally, when the temperature reaches $47^{\circ} \mathrm{C}$, the narrow MAXS peak disappears (although a broad and less intense peak seems to be present, centered at $2.70 \mathrm{~nm}$ ) and the WAXS diffractogram presents several well defined diffraction peaks. A three-dimensional crystal structure seems to be formed below this temperature.

Therefore, considering all available data, DSC, optical textures and synchrotron results, the phase transitions sequence for 2(11)OBC on cooling is the following: Isotropic $\rightarrow \operatorname{SmA}\left(101{ }^{\circ} \mathrm{C}\right)$ $\rightarrow \mathrm{SmB}\left(88^{\circ} \mathrm{C}\right) \rightarrow \mathrm{SE}\left(79^{\circ} \mathrm{C}\right) \rightarrow$ crystal phase $\left(43^{\circ} \mathrm{C}\right)$.

Phase transitions of (11)OBC: The diffraction profiles corresponding to the first melting experiment of this sample are shown in Figure 8. At low temperatures, no peak is observed in the MAXS region, while diffraction peaks are detected in the WAXS diffractogram. These characteristics, together with the texture obtained by optical microscopy, support the presence of a three-dimensional crystal structure al low temperature.

On heating, when the temperature is about $116^{\circ} \mathrm{C}$, a clearly defined MAXS peak appears, centered at $3.47 \mathrm{~nm}$, and the WAXS diffractogram shows important changes. This is attributed to the formation, totally completed at $124{ }^{\circ} \mathrm{C}$, of a highly ordered smectic crystal, probably a SE mesophase. At $c a .172{ }^{\circ} \mathrm{C}$, within a temperature range corresponding to a single frame, a new structure is evident, which is assigned to an unknown SX smectic crystal. This phase immediately transforms into a new phase where the MAXS peaks decrease significantly in intensity, while the WAXS profile is reduced to a single, relatively broad halo, indicating the formation of a smectic 
mesophase of lower order. Since the WAXS halo is not very broad, a smectic mesophase of intermediate order seems to be present. These features are typical of a mesophase with disordered hexagonal packing within the smectic layers (probably a $\mathrm{SmB}$ mesophase). A close inspection of the DSC melting curve (Figure 3) seems to indicate that the peak centered at $172.2{ }^{\circ} \mathrm{C}$ is actually composed of two overlapped endotherms, corresponding to the formation of the SX and SmB phases. On further increasing of the temperature to $c a .188{ }^{\circ} \mathrm{C}$, the MAXS peak intensity increases again, while the WAXS halo is now considerably wider and amorphous-like. This is interpreted as the formation of a low-ordered SmA mesophase, related to the small endotherm observed in the DSC curve. Finally, above $256{ }^{\circ} \mathrm{C}$ the isotropization of this mesophase is obtained.

On cooling from the isotropic melt, the phase sequence is practically the same (with an undercooling of $c a 5-10^{\circ} \mathrm{C}$ ) except for the fact that the two transitions from $\mathrm{SmB}$ to $\mathrm{SX}$ and from SX to SE are clearly resolved (see Figure 3). Therefore, considering all the DSC, optical textures and synchrotron results, the phase transitions sequence (on cooling) for (11)OBC is: Isotropic $\rightarrow$ $\mathrm{SmA}\left(246^{\circ} \mathrm{C}\right) \rightarrow \mathrm{SmB}\left(192{ }^{\circ} \mathrm{C}\right) \rightarrow \mathrm{SX}\left(162^{\circ} \mathrm{C}\right) \rightarrow \mathrm{SE}\left(148^{\circ} \mathrm{C}\right) \rightarrow$ crystal phase $\left(62^{\circ} \mathrm{C}\right)$.

On the other hand, considering that the length of the (11)OBC molecule, assuming an alltrans conformation for the alkyl chain, is calculated to be $2.58 \mathrm{~nm}$, the MAXS spacing value of $3.47 \mathrm{~nm}$ supports the presence of dimeric species, formed through intermolecular hydrogen bonds between the carboxylic groups. MAXS and IR data are thus in agreement for (11)OBC. Intercalated and/or tilted structures may be involved in the solid state for this molecule.

On the contrary, the MAXS spacings observed for 2(11)OBC (around $2.9 \mathrm{~nm}$ ) are close to the extended chain length of this molecule.

\section{CONCLUSION}

Both 4'- $n$-undecyloxybiphenyl-4-carboxylic acid, (11)OBC, and ethyl-4'-(n-undecyloxy)biphenyl-4-carboxylate, 2(11)OBC, were obtained in high yields and the latter compound has been characterized by single-crystal X-ray diffraction. Both biphenyl derivatives have high or relatively high clearing points and large liquid crystal phase ranges with a rich polymesomorphism. However, (11)OBC exhibits significantly higher clearing point and larger mesophase ranges. These differences can be ascribed to the higher polarity of the acid group, 
which probably forms dimers by hydrogen bonds associations, giving a longer mesogenic structure. The large temperatures range of the smectic mesophases, on heating and cooling, supports the existence of (11)OBC as a dimerized carboxylic acid. Therefore, the thermal behavior of (11)OBC is determined mainly by the acid group, a fact consistent with all reported data. Considering all the DSC, optical textures and synchrotron results, the phase transitions sequences for 2(11)OBC and (11)OBC were determined.

\section{ACKNOWLEDGMENTS}

This work was supported by Ministerio de Educación y Ciencia (projects MAT2004 06999 C02-01 and MAT2007 65519-C02-01), CONACYT-CSIC (2004MX0012), CONACYT fellowship 102917 and CONACYT fund 10006/55760. The synchrotron work was supported by the European Community-Research Infrastructure Action under the FP6 "Structuring the European Research Area" Program through the Integrated Infrastructure Initiative "Integrating Activity on Synchrotron and Free Electron Laser Science", contract RII3-CT-2004-506008, for the experiments in the soft-condensed matter beamline at HASYLAB. We thank the collaboration of the HASYLAB personnel, and specially Dr. S. Funari, responsible of the beam-line.

\section{SUPPORTING INFORMATION AVAILABLE}

CIF file for 2(11)OBC. This material is available free of charge via the internet at http://pubs.acs.org. 


\section{REFERENCES}

(1) Hirschmann, H.; Reiffenrath, V. in: "Handbook of Liquid Crystals" (1998), Vol. 2A, p. 199, D. Demus, J. Goodby, G. W. Gray, H.-W. Spiess, V. Vill, Eds., Wiley-VCH, Weinheim.

(2) Toyne, K. J. in: "Handbook of Liquid Crystals" (1998), Vol. 2A, p. 47, D. Demus, J. Goodby, G. W. Gray, H.-W. Spiess, V. Vill, Eds., Wiley-VCH, Weinheim.

(3) Mcardle, C. B. Side Chain Liquid Crystal Polymers (1989). p. 357. Blackie and Son Ltd, London.

(4) Gray, G. W.; Hartley, J. B; Jones, B. J. Chem. Soc. 1955, 1412.

(5) Isoo, K; Takayuki, H.; Shoji, T; Masayashi, M; Chizu, S; Takeshi, T. Chem. Abstr. 1990, 115 $18727 \mathrm{~V}$.

(6) XSCAnS (release 2.21) Users Manual, Siemens Analytical X-ray Instruments Inc., Madison, WI, USA (1996).

(7) G. M. Sheldrick, SHELX97 Users Manual, University of Göttingen, Germany (1997).

(8) Vogel, A. I.; Tatchell, A. R.; Furnis, B. S.; Hannaford, A. J. (1996). Vogel's Textbook of Practical Organic Chemistry. p. 1552. 5th Edition. Ed. Prentice Hall.

(9) Rajnikant; Gupta, V. K.; Dinesh; Kumar, A.; Varghese, B. Kristallografiya 2003, 48, 321.

(10) Rajnikant; Gupta, V. K.; Gupta, R.; Kumar, A.; Bamezai, R. K.; Sharma, N. K.; Varghese, B. Kristallografiya 2000, 45, 104.

(11) Rajnikant; Gupta, V. K.; Dinesh; Kumar, A.; Varghese, B. Mol. Cryst. Liq. Cryst. Sci. Technol. 2002, A383, 99. 
(12) Hori, K.; Kurosaki, M.; Wu, H.; Itoh, K. Acta Crystallogr. 1996, 52, 1751.

(13) Davey, R. J.; Gillon, A. L.; Quayle, M. J.; Rashad, O. Acta Crystallogr. 2005, 61, 143

(14) Lee, J. Y.; Painter, P. C.; Coleman, M. M. Macromolecules 1988, 21, 954.

(15) Kato, T; Fréchet J. M. J. Macromolecules 1989 22, 3818.

(16) March, J. (1992), Advanced organic chemistry: reactions, mechanism and structure, p.75, $4^{\text {th }}$ ed. John Wiley \& Sons, Inc., New York.

(17) Demus, D.; Richter, L. "Textures of Liquid Crystals", 2nd ed., VEB Deutscher Verlag für Grundstoffindustries, Leipzig 1980.

(18) Bouligand, Y. in: "Handbook of Liquid Crystals" (1998), Vol. 1, p. 406, D. Demus, J. Goodby, G. W. Gray, H.-W. Spiess, V. Vill, Eds., Wiley-VCH, Weinheim.

(19) Chandrasekhar, S. (1992) Liquid Crystals, $2^{\text {nd }}$. Ed., Cambridge University Press, Cambridge. 
Table 1. Thermal properties and phase transitions involved for 2(11)OBC and (11)OBC in the first DSC heating run.

\begin{tabular}{|c|c|c|c|c|}
\hline Sample & $T,{ }^{\circ} \mathrm{C}(\Delta H, \mathrm{~J} / \mathrm{g})$ & $T,{ }^{\circ} \mathrm{C}(\Delta H, \mathrm{~J} / \mathrm{g})$ & $T,{ }^{\circ} \mathrm{C}(\Delta H, \mathrm{~J} / \mathrm{g})$ & $T,{ }^{\circ} \mathrm{C}(\Delta H, \mathrm{~J} / \mathrm{g})$ \\
\hline 2(11)OBC & SE $79.0(90.8)$ & SmB 81.8 (3.0) & SmA $90.0(7.0)$ & I $104.0(25.5)$ \\
\hline (11)OBC & SE 115.8 (63.3) & SX+SmB $172.2(45.3)$ & SmA $200.5(2.0)$ & I $254.2(56.0)$ \\
\hline
\end{tabular}

$\mathrm{I}=$ isotropic, $\mathrm{SmA}=$ Smectic $\mathrm{A}, \mathrm{SmB}=$ Smectic $\mathrm{B}, \mathrm{SE}=$ Smectic crystal E, $\mathrm{SX}=$ unknown smectic crystal.

Table 2. Thermal properties and phase transitions involved for 2(11)OBC and (11)OBC in the DSC cooling from the isotropic melt.

\begin{tabular}{|l|r|l|l|l|}
\hline \multicolumn{1}{|c|}{ Sample } & $T,{ }^{\circ} \mathrm{C}(\Delta H, \mathrm{~J} / \mathrm{g})$ & \multicolumn{1}{|c|}{$T,{ }^{\circ} \mathrm{C}(\Delta H, \mathrm{~J} / \mathrm{g})$} & \multicolumn{1}{c}{${ }^{\circ} \mathrm{C}(\Delta H, \mathrm{~J} / \mathrm{g})$} & $T,{ }^{\circ} \mathrm{C}(\Delta H, \mathrm{~J} / \mathrm{g})$ \\
\hline 2(11)OBC & SmA $100.9(24.8)$ & SmB $87.6(6.7)$ & SE 78.7 (5.6) & K 43.4 (57.8) \\
\hline (11)OBC & SmA 246.3 (56.4) & SmB 191.6 (2.1) & SX 162.1 (32.1) & K 61.9 (12.6) \\
& & & SE 148.3 (12.3) & \\
\hline
\end{tabular}

$\mathrm{SmA}=$ Smectic $\mathrm{A}, \mathrm{SmB}=$ Smectic $\mathrm{B}, \mathrm{SE}=$ Smectic crystal E, $\mathrm{SX}=$ unknown smectic crystal, $\mathrm{K}=$ crystal. 

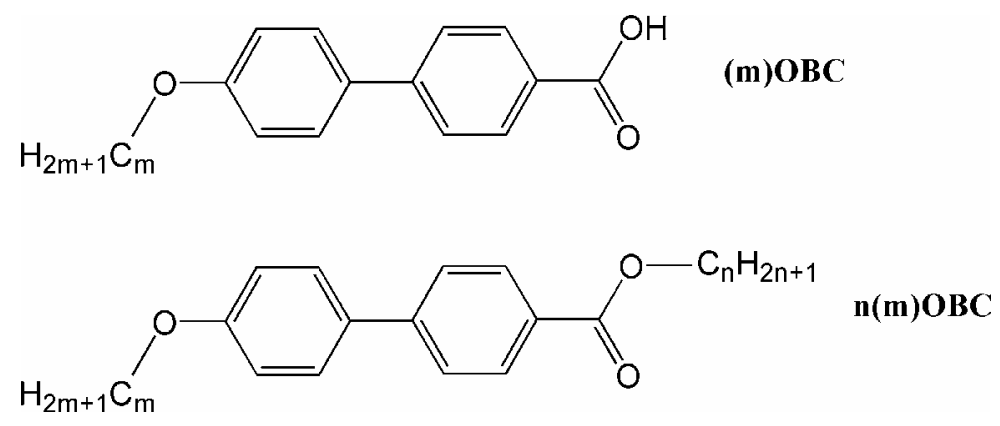

Scheme 1. General formula of 4'-n-alkoxybiphenyl-4-carboxylates and n-alkyl-4'-nalkoxybiphenyl-4-carboxylates.

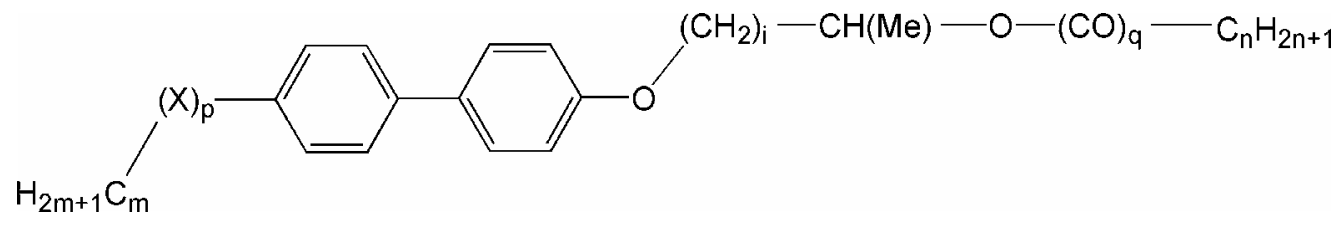

Scheme 2. Optically active biphenyl derivatives ${ }^{5}$, where $\mathrm{X}=\mathrm{O}, \mathrm{CO}$ or $\mathrm{OCO} ; p, q=0$ or 1 and $\boldsymbol{i}=1-6 ; \boldsymbol{m}=3-20 ; \boldsymbol{n}=1-20$ (optionally substituted).

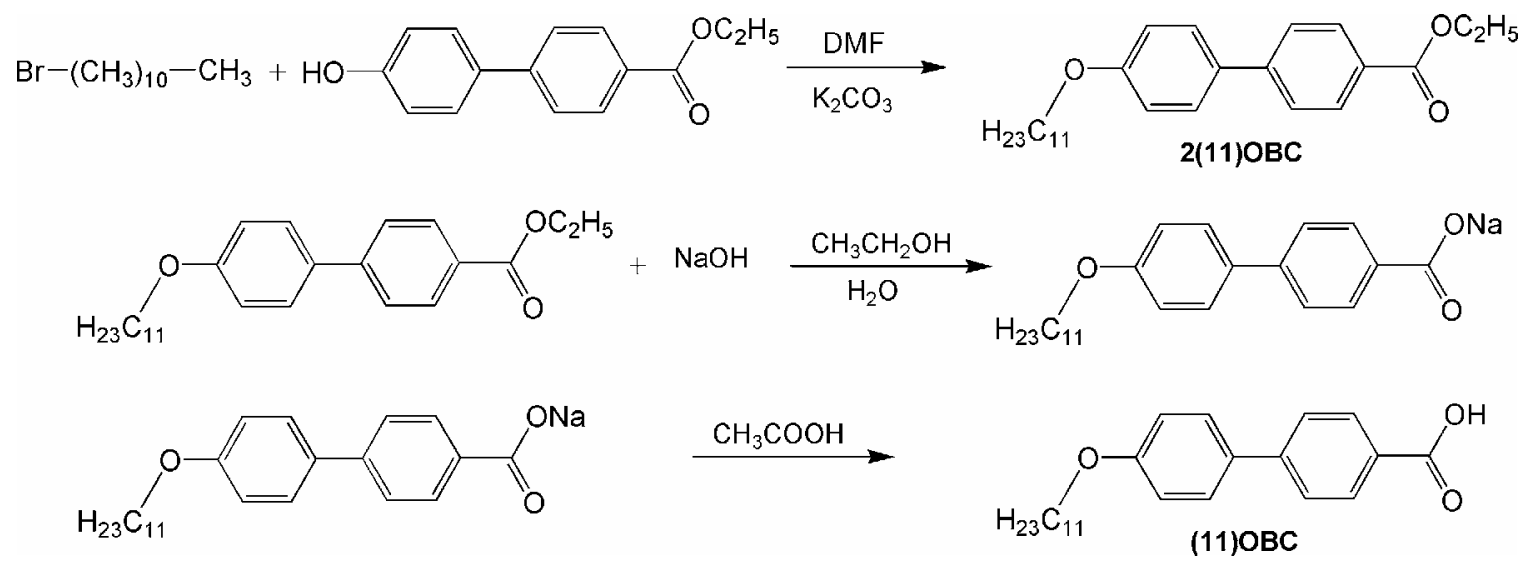

Scheme 3. Synthesis of 2(11)OBC and (11)OBC. 


\section{FIGURES CAPTIONS}

Figure 1. Crystal structure of 2(11)OBC viewed along [001]. Left molecules are in a stick style while right molecules are shown in a spacefill style, in order to appreciate how molecules stack along [010]. Colors for spacefill molecules are arbitrary. The inset represents an ORTEP-like plot of 2(11)OBC, with displacement ellipsoids for non-H atoms at the 50\% probability level.

Figure 2. Thermogravimetric curve of (11)OBC.

Figure 3: DSC curves of the biphenyl derivative (11)OBC corresponding to the first melting and the subsequent cooling.

Figure 4: DSC curves of the biphenyl derivative 2(11)OBC corresponding to the first melting and the subsequent cooling.

Figure 5. Optical textures, at the indicated temperatures, of (11)OBC on cooling from the isotropic melt.

Figure 6. Optical textures, at the indicated temperatures, of 2(11)OBC on cooling from the isotropic melt.

Figure 7: MAXS (left) and WAXS (right) profiles corresponding to the monomer 2(11)OBC in a cooling experiment from the isotropic melt.

Figure 8: MAXS (left) and WAXS (right) profiles for the biphenyl derivative (11)OBC in the first melting experiment. 


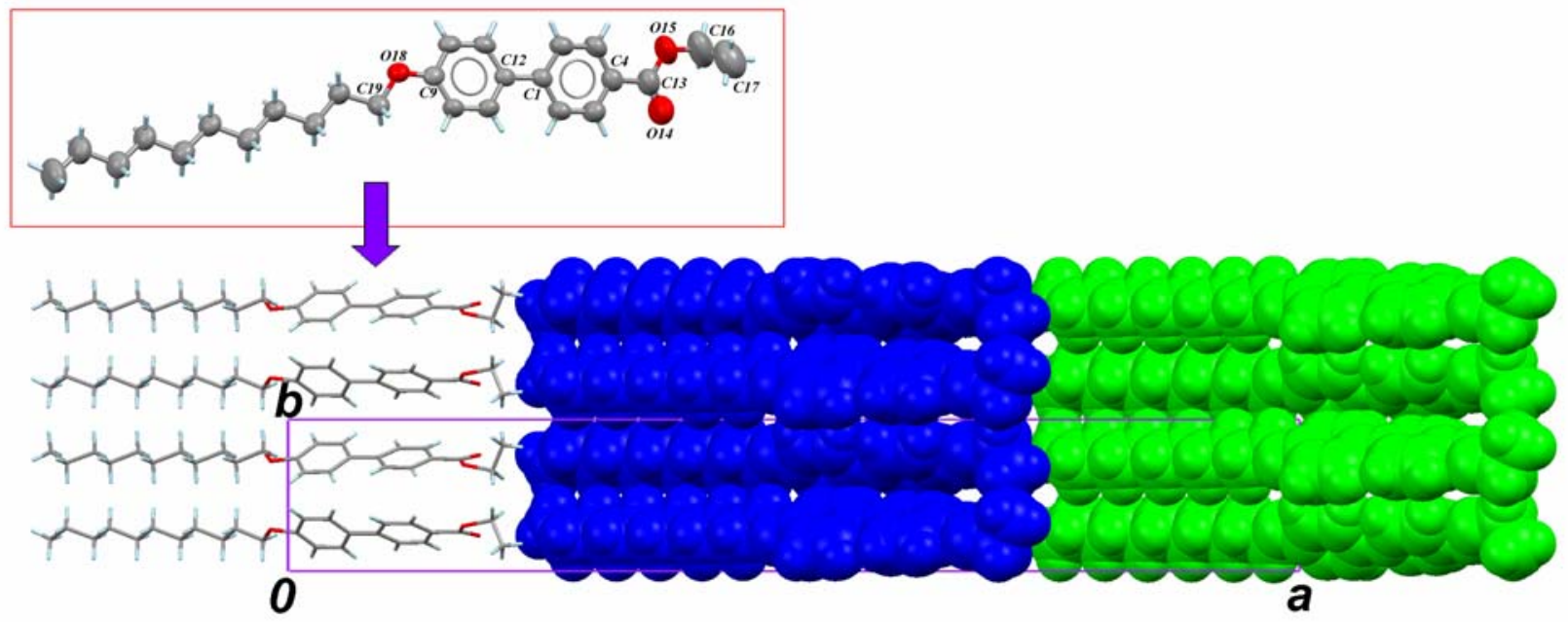

Figure 1 


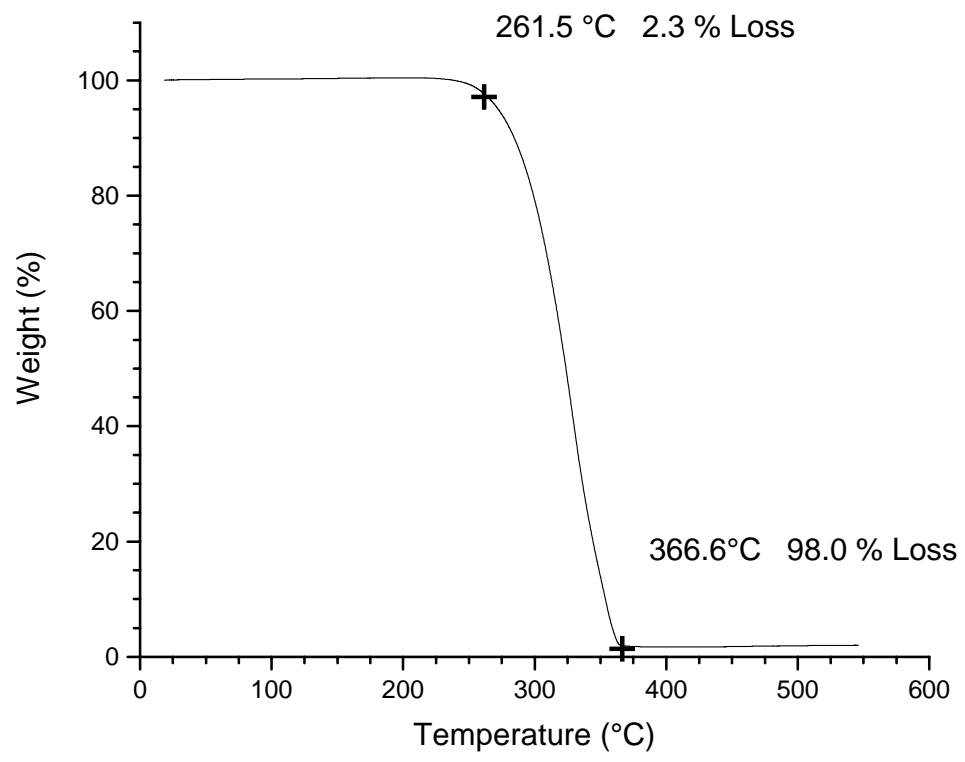

Figure 2 


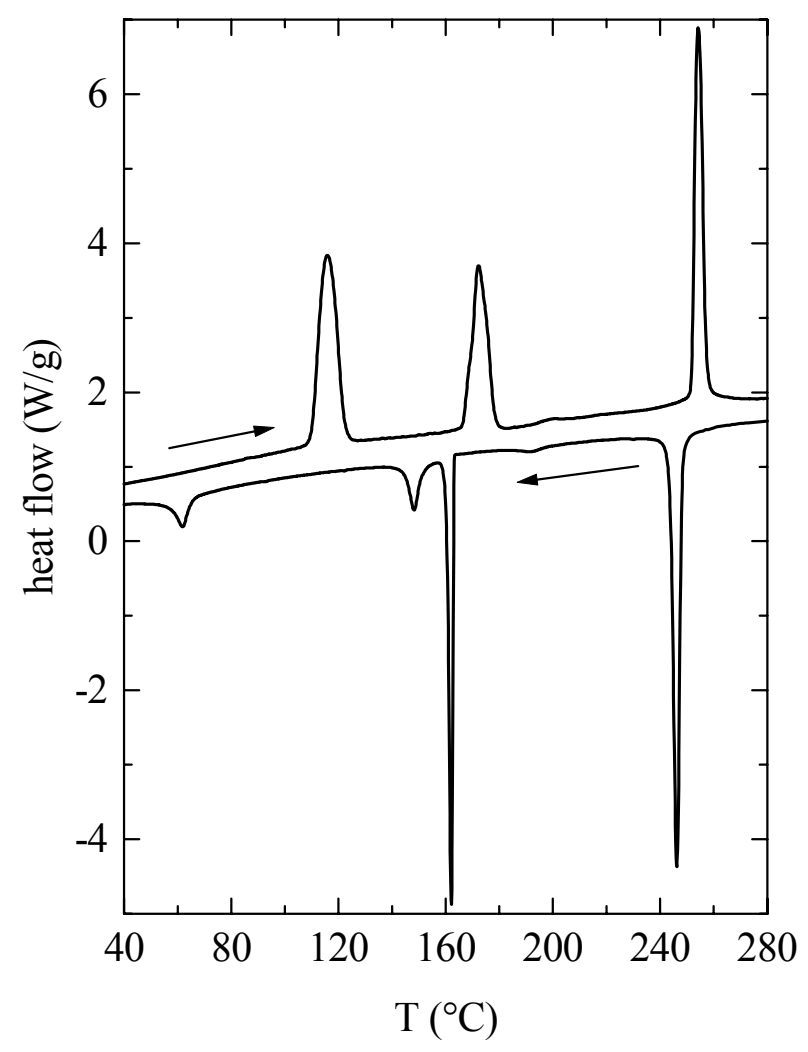

Figure 3 


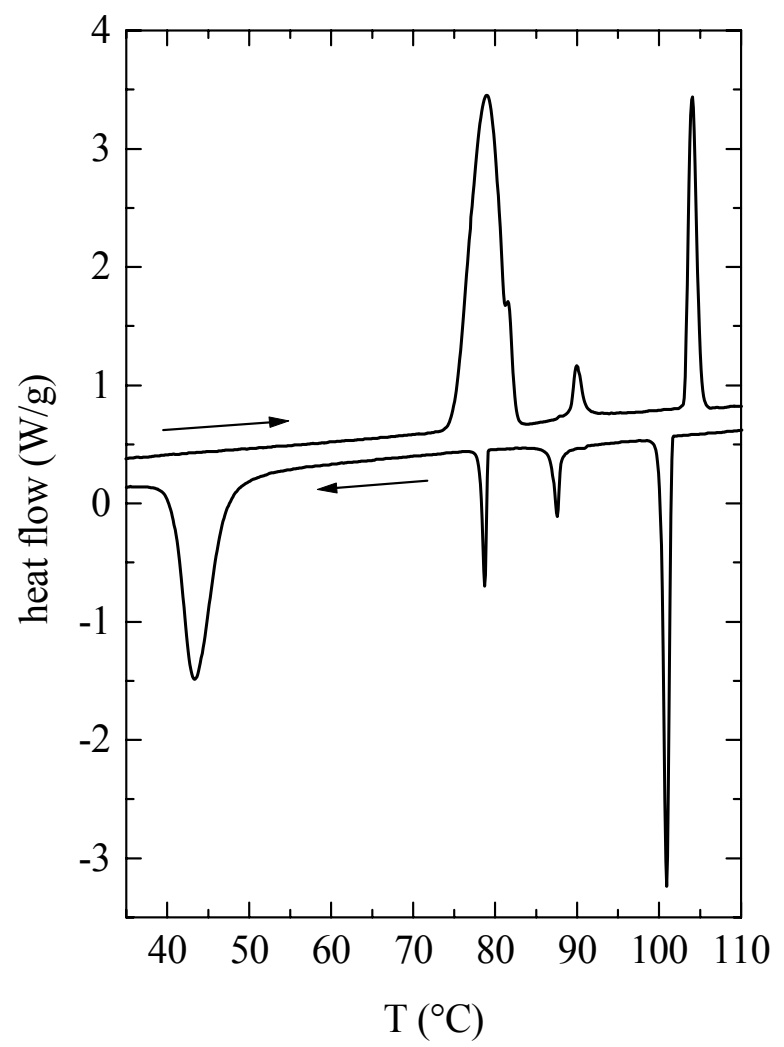

Figure 4 
a) $240{ }^{\circ} \mathrm{C}$

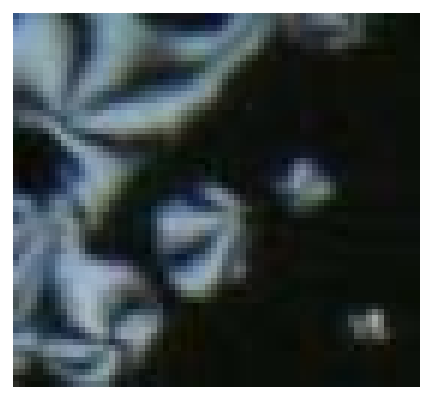

c) $135^{\circ} \mathrm{C}$

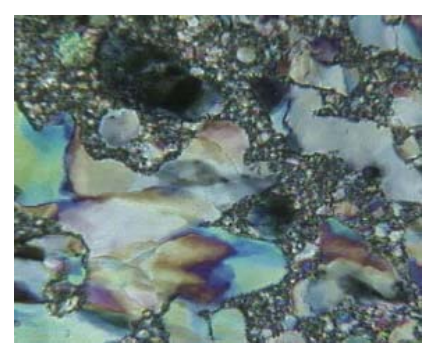

b) $230{ }^{\circ} \mathrm{C}$

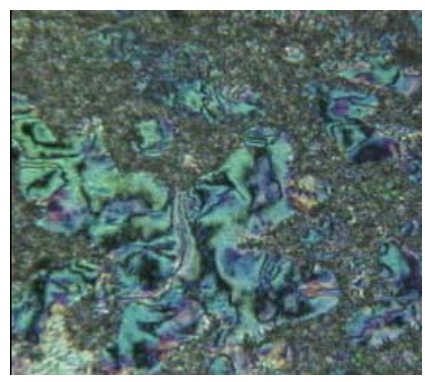

d) $60{ }^{\circ} \mathrm{C}$

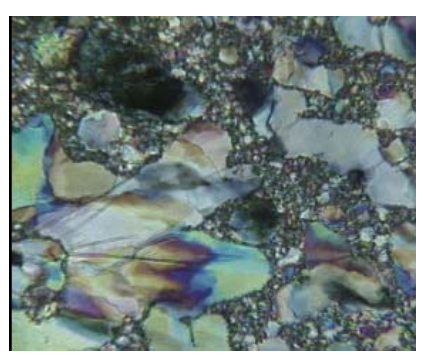

Figure 5 
a) $103{ }^{\circ} \mathrm{C}$

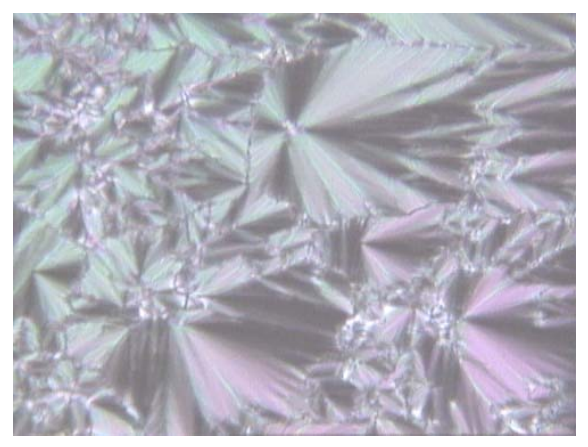

c) $75^{\circ} \mathrm{C}$

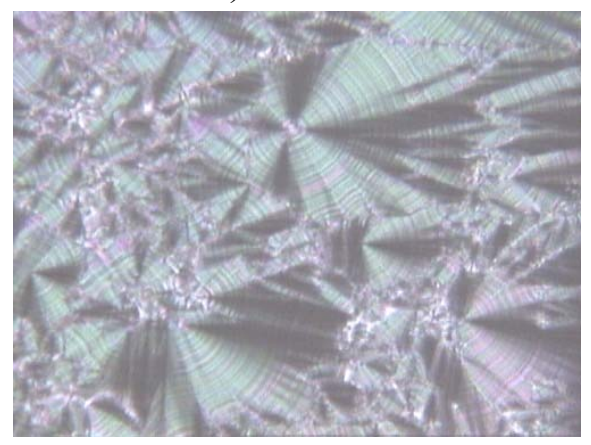

b) $85^{\circ} \mathrm{C}$

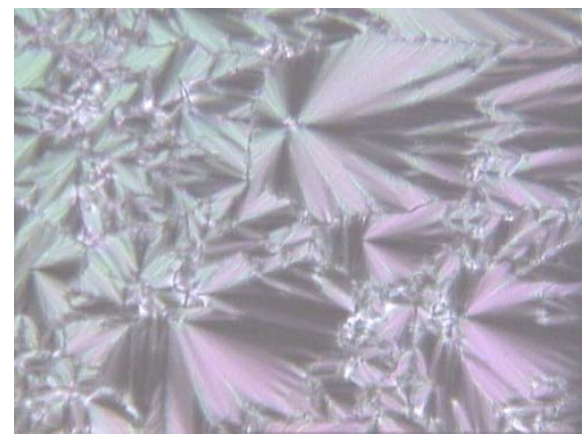

d) $31{ }^{\circ} \mathrm{C}$

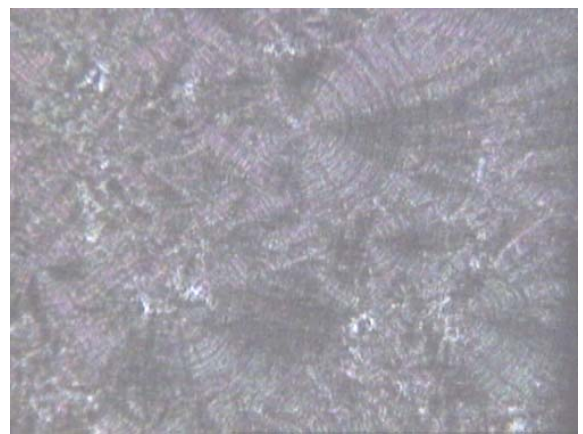

Figure 6 

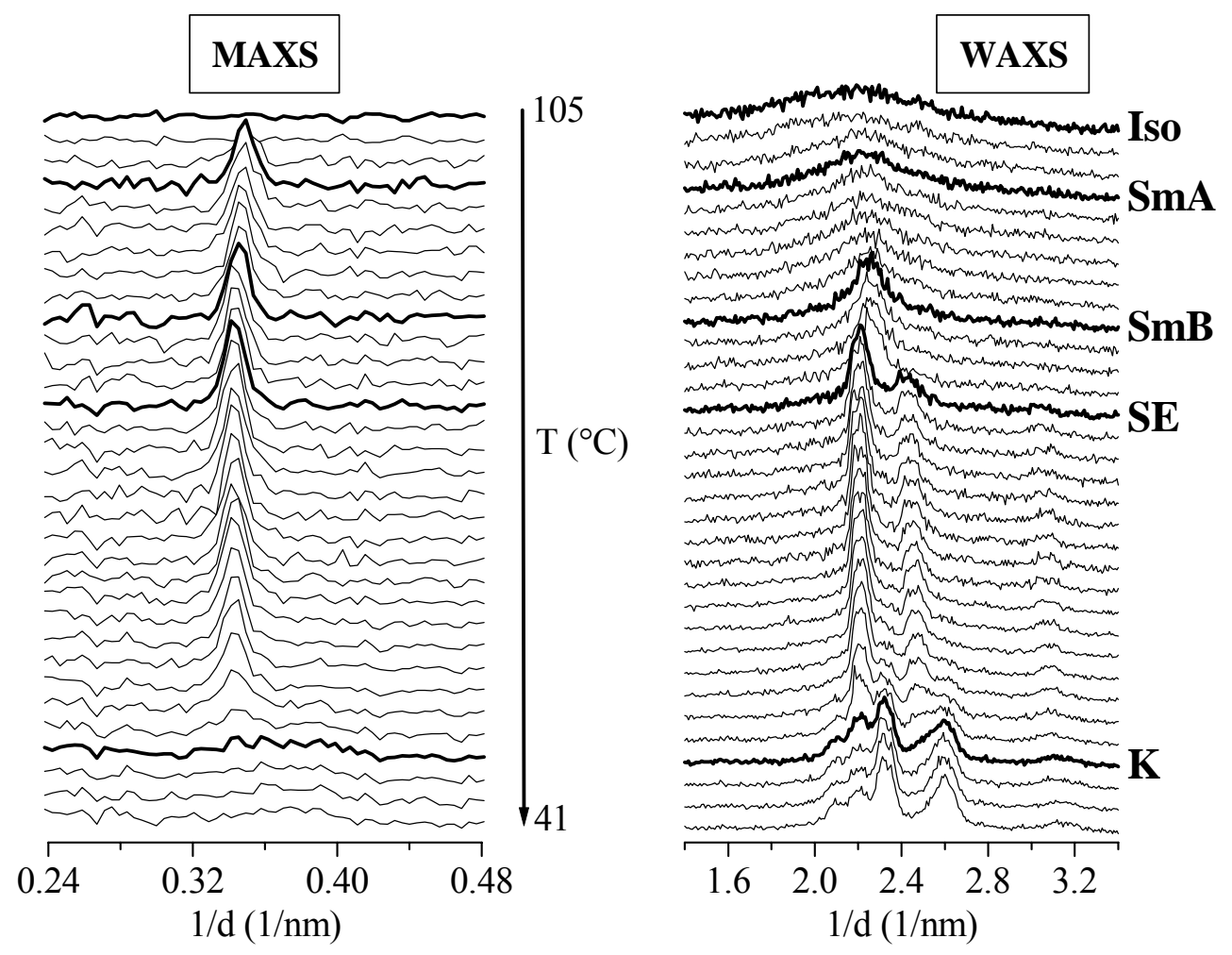

Figure 7 

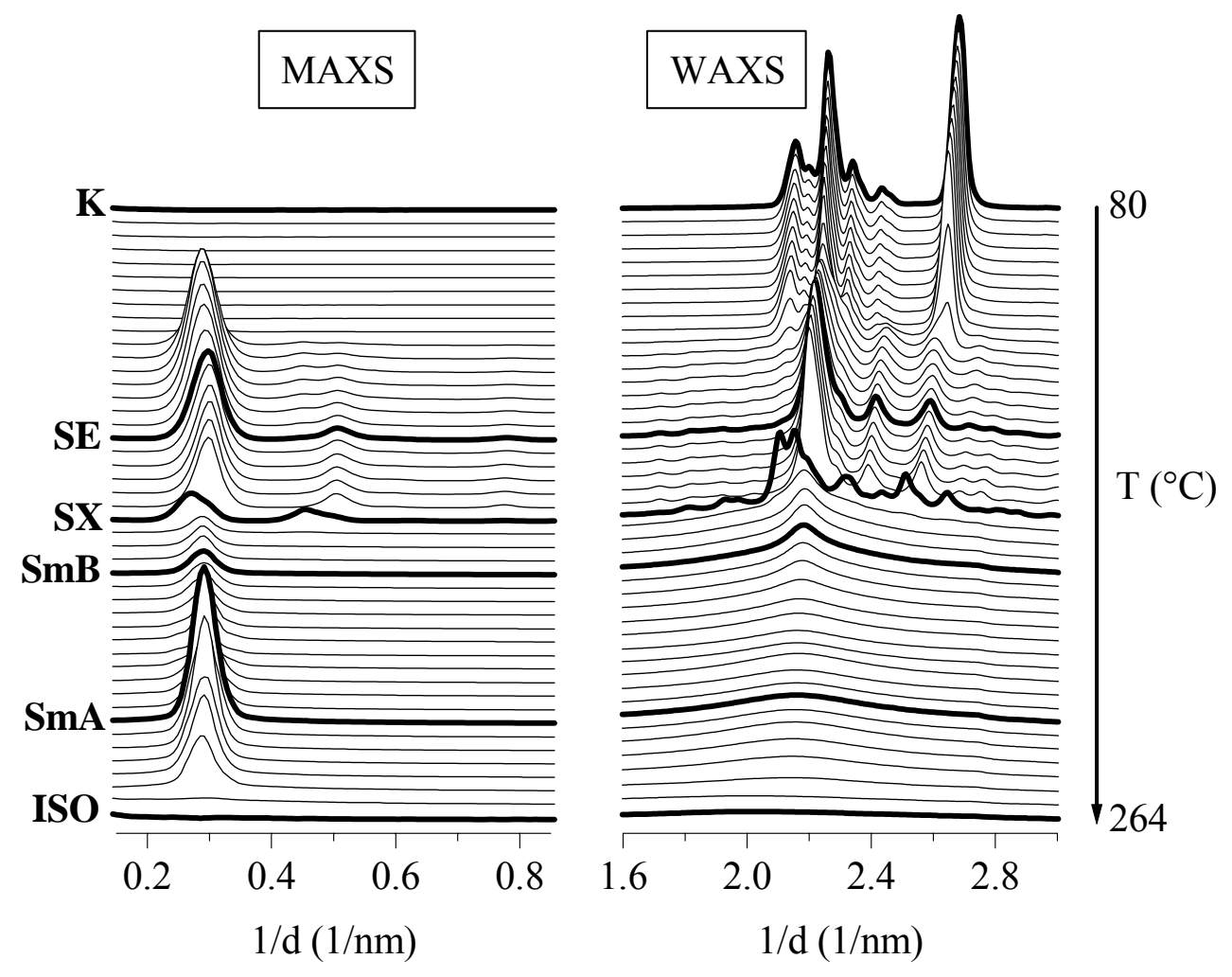

Figure 8 